\title{
Fiber Identification from Ethiopian Ladies Skirt
}

\author{
Lami Amanuel* \\ Department of Textile Engineering, Wollo University, Ethiopia, Africa
}

Submission: September 22, 2017; Published: October 27, 2017

*Corresponding author: Lami Amanuel, Department of Textile Engineering, Kombolcha Institute of Technology, Ethiopia, Africa, Email: lamiamanuel@gmail.com

\begin{abstract}
Along with the trend toward automation in the textile industry, an objective, correct, and efficient fiber identification method and blend analysis has become an important component of rapid respondent systems the textile industry desires. This research is doing component and percentage quantity analysis for fabrics imported to Ethiopia at present situation for ladies skirts. Identification and analysis is done by assessing fiber hand touch feeling characteristics, burning nature, longitudinal microscopic appearance, solubility in many chemical solvents and blend ratio analysis calculation. Most of the fabrics imported to Ethiopia for ladies skirt are synthetics and blend of synthetics like polyester, acrylic ,blend of polyester and wool, blend of polyester and cotton, blend of polyester, cotton and wool, blend of polyester, acrylic and wool, blend of polyester and acrylic, blend of polyester and nylon ,blend of polyester ,nylon and cotton. Polyester is the major of which imported in single component and blended with others. Some fabrics contain Lycra spandexes which give better stretch ability. Considering the comfort, cost effectiveness and serviceability blend of polyesters with natural are highly desired by Ethiopian ladies. Therefore it is advantageous to produce these kinds of fabrics the country for the future to satisfy the Ethiopian ladies need.
\end{abstract}

Keywords: Fiber identification, Blend analysis, Ladies skirts, Solubility, Longitudinal microscopic appearance

\section{Introduction}

Nowadays wearing skirt is becoming a fashion and many styles of skirt are introduced. Ethiopian ladies wear skirts more than other country ladies. This shows that our country imports many finished fabrics which have different characteristics, services and costs. The style of the skirts can be made during sewing i.e. garment formation, finishing types given during wet processing, weaving mechanism and the type of the fiber/s used. To identify and analyze any type of skirt from which fiber/s is made, the study of textile fibers has become a very interesting and challenging science. This study is related to their identification methods and blend analysis techniques of the type/s of the fiber/s. The textile fiber products Identification Act requires that the manufacturers of cloth garments and household textiles attach labels to their products specifying the fiber content. These manufacturers are expected to know this information since it is they who tell the fabric producers the requirements for the fabrics they intended to purchase. Should product manufacturers to identify or verify the fiber content; they must be in a position either to make the appropriate technical analysis or refer samples to a testing laboratory [1].

The retailer, in turn, is held responsible under the act to see that labels or hangtags are attached to the textile products before being sold. Reliance must be placed on the retailer's vendor to provide properly labeled merchandise. Sometimes imported merchandise arrives unlabeled or sometimes labels become detached and lost. It is then the merchant's responsibility to get appropriate labels and to attach them to the merchandise [2].

Ready recognition and identification of fiber content in fabrics has become extremely difficult even for knowledgeable and experienced merchants because of the growing variety of types of fibers, the blending techniques in yarn and fabric construction and the finishes that affect the appearance and hand of the fabrics. Therefore, certain laboratory tests are used for identification and verification [2].

The consumer has the greatest difficulty in identifying fiber content of fabrics. Should the identification and/or care labels be mutilated or lost from textile product, one may not know the composition of the fabric and therefore not know what to expect of it. Because one is usually not in a position to make a laboratory analysis, reliance must be placed up on certain nontechnical tests. A dye house or a dyeing enterprise should have a well qualified or shelled technical to identify the composition or fiber type supplied before processing. This is important to prepare the right recipe (formulation) and select suitable dye, machinery and processing [2]. 
Garment industry, custom, quality and standardization authorities and ministry of revenue should have a well qualified technique to identify the fiber type supplied from any country to control the quality and to confirm the customer requirements. Fabrics imported to our country have to be identified and analyzed their quality and percentage quantity composition, since it is necessary to decide the quality and cost of the fabrics based on their type and component.

\section{Materials and Methods}

\section{Materials}

a. Finished fabrics: Different types of finished fabrics of different weight, composition, surface character, color, with no specified ratio of different blends in their labels.

b. Chemicals: Sulphuric acid (998\% BDH), hydrochloric acid (36\%BDH), glacial acetic acid (BDH), formic $\operatorname{acid}(\mathrm{BDH})$, nitric acid (69-72\% BSSEX England), sodium hydroxide(Pellets) and acetone (EEC).

c. Equipments and Apparatus: Different equipments, which are found in the wet processing and fiber-testing laboratory, have been used.

\subsection{Methods}

The experiment must do stepwise to save time, material and cost. Thus as we have done our experiment the steps to reduce these things are as follow below respective. a. Feeling test: By handling both sides of the fabric gently in three rounds, stretching the fabric holding with our hand and observing the coolness/warmness, smoothness, softness and elasticity of each fabrics.

b. Burning test: By holding the individual fabric samples to be tested in our hand and bring the fabric slowly to the side of a candle burner flame and withdrawing it. We have observed the initial reaction of the fabric and the flame, flame description, odour, extinguishable nature and residue of the burned fabric.

c. Microscopic test (longitudinal): By separating the yarns into fibers we have put the fibers into watch glass or slider, and then to the sample place and viewing the longitudinal appearance.

d. Solubility Test: By taking a piece of warps and wefts having $1 \mathrm{gm}$ each from each fabric as a sample we put into the solutions and stirring occasionally. By removing what is left into a beaker of water with care we have stirred once more, weighing the un dissolved component, we have calculated the percentage of the blend ratio.

\section{Result and Discussion}

From the experiment we have already done as explained above we have obtained significant results for each the feeling, burning, microscopic and solubility tests. The results are listed in the following four tables.

\section{Feeling effect}

Table 1: Feeling character of fabrics obtained.

\begin{tabular}{|c|c|c|c|}
\hline Sample no. & Hand feeling test & Sample no. & Hand feeling test \\
\hline 1. & Smooth, inelastic & 11 & Slightly smooth, soft, elastic \\
\hline 2. & Slightly soft, slightly smooth, inelastic, cool & 12 & Smooth, stiff, inelastic \\
\hline 3. & Slightly slippery, warm, inelastic, light weight & 13 & Slightly smooth, slightly soft, elastic \\
\hline 4. & $\begin{array}{c}\text { Smooth, inelastic, some yarns are smooth } \\
\text { elastic and lustrous woven in weft direction }\end{array}$ & 14 & Slightly smooth, elastic, stiff \\
\hline 5. & Smooth, stiff, inelastic & 15 & Smooth, heavyweight, elastic, some fibers are lustrous woven in \\
weft direction
\end{tabular}

This result is obtained by gentle handling of the two sides of the fabric surfaces. The fabrics we have tested have different smoothness, softness, stiffness and elasticity but this depends also on the finishing technique given to the fabric and its construction. The handling sensation of each fabric is in the Table 1 below. 


\section{Burning nature}

When we bring to flame, all most all the fabrics shrinks and then burn giving yellow orange flame with different odors. During burning some fibers distinguish themselves and others

Table 2: Burning nature of fabrics observed.

\begin{tabular}{|c|c|c|c|c|c|c|}
\hline Sample & $\begin{array}{l}\text { Initial } \\
\text { reaction }\end{array}$ & $\begin{array}{c}\text { Flam } \\
\text { description }\end{array}$ & Smell & Self-extinguish & Residue & Expected fibers \\
\hline 1 & \multirow{20}{*}{ Shrink } & \multirow{20}{*}{ Yellow orange } & Odorless & Extinguish & Solidified melt & Synthetic \\
\hline 2 & & & Paper burning & Distinguish & Solidified melt & $\begin{array}{c}\text { Blend of cotton or viscose rayon } \\
\text { with synthetics }\end{array}$ \\
\hline 3 & & & Odorless & Extinguish & Hard, dark, brittle melt & Synthetic \\
\hline 4 & & & Odorless & Extinguish & Solidified melt & Synthetic \\
\hline 5 & & & Odorless & Distinguish & Solidified melt & Synthetic \\
\hline 6 & & & Plastic burning & Distinguish & Hard, dark, brittle melt & Synthetic \\
\hline 7 & & & Odorless & Distinguish & Solidified melt & Synthetic \\
\hline 8 & & & Pungent & Extinguish & Hard, black bead & Synthetic \\
\hline 9 & & & Odorless & Distinguish & $\begin{array}{l}\text { Hard, dark, solidified } \\
\text { melt }\end{array}$ & Synthetic \\
\hline 10 & & & Odorless & Extinguish & Hard, dark melt & Synthetic \\
\hline 11 & & & Paper burning & Distinguish & Slightly hard ash & $\begin{array}{l}\text { Blend of cotton or viscose rayon } \\
\text { with synthetic }\end{array}$ \\
\hline 12 & & & Odorless & Distinguish & Solidified melt & Synthetic \\
\hline 13 & & & Odorless & Distinguish & Hard, dark, brittle melt & Synthetic \\
\hline 14 & & & Paper burning & Extinguish & Hard, dark ash & $\begin{array}{l}\text { Blend of cotton or viscose rayon } \\
\text { with synthetics }\end{array}$ \\
\hline 15 & & & Rubber burning & Distinguish & Solidified ash & Synthetic \\
\hline 16 & & & Feather burning & Extinguish & Black, hard, brittle ash & $\begin{array}{l}\text { Blend of wool or silk with } \\
\text { synthetic }\end{array}$ \\
\hline 17 & & & Paper burning & Distinguish & Brittle melted ash & $\begin{array}{l}\text { Blend of cotton or viscose rayon } \\
\text { with synthetics }\end{array}$ \\
\hline 18 & & & Plastic burning & Distinguish & Glassy, solidified melt & Synthetic \\
\hline 19 & & & Plastic burning & Extinguish & Solidified melt & Synthetic \\
\hline 20 & & & Pungent or bad & Distinguish & Hard melted ash & Synthetic \\
\hline
\end{tabular}

\section{Longitudinal viewed appearances}

Different longitudinal views were obtained even in one fabric. Some fibers with rod like or circular straight longitudinal appearance, some fibers have fewer margins, and some fibers

Table 3: Longitudinal viewed appearances of the fabric.

\begin{tabular}{|c|c|c|c|c|c|}
\hline $\begin{array}{l}\text { Sample } \\
\text { No. }\end{array}$ & Longitudinal view & Expected fiber & Sample No. & Longitudinal view & $\begin{array}{l}\text { Expected } \\
\text { fiber }\end{array}$ \\
\hline 1 & Regular, rod like & Synthetic & 11 & Regular, rod like, black thick, white thin & Synthetic \\
\hline 2 & Smoother, fewer convolution & Cotton & 12 & Regular, rod like & Synthetic \\
\hline 3 & Straight, smooth rod like & Synthetic & 13 & $\begin{array}{l}\text { Some fibers have fewer margins and others are } \\
\text { straight rod like }\end{array}$ & $\begin{array}{l}\text { Blend of wool } \\
\text { and synthetic }\end{array}$ \\
\hline 4 & $\begin{array}{l}\text { Body rod like, brown and } \\
\text { sliver yarns smooth variable } \\
\text { in diameter }\end{array}$ & $\begin{array}{l}\text { Blend of silk and } \\
\text { synthetic }\end{array}$ & 14 & $\begin{array}{l}\text { Some fibers have fewer convolutions and } \\
\text { others are straight rod like }\end{array}$ & $\begin{array}{l}\text { Blend of } \\
\text { Cotton and } \\
\text { synthetic }\end{array}$ \\
\hline 5 & Very regular, rode like & Synthetic & 15 & $\begin{array}{c}\text { Some fibers rod like Some fibers variable in } \\
\text { diameter }\end{array}$ & Blend of Silk \\
\hline
\end{tabular}

extinguish in the opposite manner. In this method we have identified fabrics containing cotton or wool blended with other fabrics depending on their odour, self-extinguish ability and residues obtained Table 2 . 


\section{Current Trends in Fashion Technology \& Textile Engineering}

\begin{tabular}{|c|c|c|c|c|c|}
\hline 6 & Straight and smooth & Synthetic & 16 & $\begin{array}{c}\text { Some fibers have fewer convolutions, Some } \\
\text { fibers are rod like, Some fibers have fewer } \\
\text { scales }\end{array}$ & $\begin{array}{c}\text { Blend of } \\
\text { Cotton, wool } \\
\text { and synthetic }\end{array}$ \\
\hline 7 & Regular, rod like & Synthetic & 17 & $\begin{array}{c}\text { Some fibers have convolutions } \\
\text { Some fibers are thin rod like } \\
\text { Some fibers are thick rod like }\end{array}$ & $\begin{array}{c}\text { Blend of } \\
\text { Cotton, } \\
\text { synthetic and } \\
\text { synthetic }\end{array}$ \\
\hline 8 & Regular, rod like & Synthetic & 18 & Regular, rod like & Synthetic \\
\hline 9 & Regular, rod like and straight & Synthetic & 19 & Regular, rod like & Synthetic \\
\hline 10 & Rod like and straight & Synthetic & 20 & Some fibers have convolutions & Blend of \\
Cotton and \\
synthetic
\end{tabular}

\section{Solubility}

By feeling, burning and microscope test we identified natural fibers from synthetic fibers and cellulosic fibers (cotton) from protein fibers (wool and silk). Within solubility test we have indicated each definite groups and specific fibers.

By this method we have obtained two forms of blend fabrics i.e. blending takes place at;

Table 4: Weight of undisclosed components of the fabrics in gm.

\begin{tabular}{|c|c|c|c|c|c|c|c|c|c|}
\hline \multicolumn{2}{|c|}{ Sample No. } & \multirow{2}{*}{$\begin{array}{c}\mathrm{H} 2 \mathrm{SO} 4 \\
\mathbf{7 5 \%} \\
1\end{array}$} & \multirow{2}{*}{$\begin{array}{c}\text { NaOH boiling } \\
\mathrm{d}\end{array}$} & \multirow{2}{*}{$\begin{array}{c}\mathrm{NaOH} \\
1\end{array}$} & \multirow{2}{*}{$\begin{array}{c}\text { HNO3 } \\
100 \% \\
1\end{array}$} & \multirow{2}{*}{$\begin{array}{c}\mathrm{HCl} 28 \% \\
1\end{array}$} & \multirow{2}{*}{$\begin{array}{c}\begin{array}{c}\text { Formic } \\
\mathbf{1 0 0 \%}\end{array} \\
1\end{array}$} & \multirow{2}{*}{$\begin{array}{c}\text { Glacial acetic boiling } \\
1\end{array}$} & \multirow{2}{*}{$\begin{array}{c}\text { Acetone } \\
1 \\
\end{array}$} \\
\hline & Warp & & & & & & & & \\
\hline 1 & Weft & 1 & $\mathrm{~d}$ & 1 & 1 & 1 & 1 & 1 & 1 \\
\hline \multirow{2}{*}{2} & Warp & 0.21 & 0.79 & 1 & 0.22 & 1 & 1 & 1 & 1 \\
\hline & Weft & 0.21 & 0.81 & 1 & 0.21 & 1 & 1 & 1 & 1 \\
\hline \multirow{2}{*}{3} & Warp & 1 & 1 & 1 & d & 1 & 1 & 1 & 1 \\
\hline & Weft & 1 & 1 & 1 & d & 1 & 1 & 1 & 1 \\
\hline \multirow{2}{*}{4} & Warp & 1 & $\mathrm{~d}$ & 1 & 1 & 1 & 1 & 1 & 1 \\
\hline & Weft & 0.92 & $\mathrm{~d}$ & 0.91 & 0.91 & 0.91 & 1 & 1 & 1 \\
\hline \multirow{2}{*}{5} & Warp & 1 & $\mathrm{~d}$ & 1 & 1 & 1 & 1 & 1 & 1 \\
\hline & Weft & 1 & $\mathrm{~d}$ & 1 & 1 & 1 & 1 & 1 & 1 \\
\hline 6 & Knit & 0.76 & 1 & 1 & 0.07 & 1 & 0.76 & 0.76 & 1 \\
\hline \multirow{2}{*}{7} & Warp & 1 & d & 1 & 1 & 1 & 1 & 1 & 1 \\
\hline & Weft & 1 & $\mathrm{~d}$ & 1 & 1 & 1 & 1 & 1 & 1 \\
\hline \multirow{2}{*}{8} & Warp & 0.50 & 0.53 & 1 & 0.48 & 1 & 0.53 & 0.51 & 1 \\
\hline & Weft & 0.51 & 0.52 & 1 & 0.49 & 1 & 0.51 & 0.52 & 1 \\
\hline \multirow{2}{*}{9} & Warp & 1 & 0.44 & 1 & 0.55 & 1 & 1 & 1 & 1 \\
\hline & Weft & 1 & 0.45 & 1 & 0.54 & 1 & 1 & 1 & 1 \\
\hline 10 & Knit & 0.78 & 1 & 1 & 0.07 & 1 & 0.78 & 0.78 & 1 \\
\hline \multirow{2}{*}{11} & Warp & 1 & $\mathrm{~d}$ & 1 & 1 & 1 & 1 & 1 & 1 \\
\hline & Weft & 0.42 & 0.60 & 1 & 0.59 & 1 & 0.81 & 0.80 & 1 \\
\hline \multirow{2}{*}{12} & Warp & 1 & $\mathrm{~d}$ & 1 & 1 & 1 & 1 & 1 & 1 \\
\hline & Weft & 1 & $\mathrm{~d}$ & 1 & 1 & 1 & 1 & 1 & 1 \\
\hline \multirow{2}{*}{13} & Warp & 1 & $\mathrm{~d}$ & 0.51 & 1 & 1 & 1 & 1 & 1 \\
\hline & Weft & 1 & $\mathrm{~d}$ & 0.50 & 1 & 1 & 1 & 1 & 1 \\
\hline \multirow{2}{*}{14} & Warp & 0.55 & 0.46 & 1 & 0.55 & 1 & 1 & 1 & 1 \\
\hline & Weft & 0.54 & 0.44 & 1 & 0.54 & 1 & 1 & 1 & 1 \\
\hline
\end{tabular}

a. Yarn stage: the blend takes place at spinning stage So, the fabrics have a blended yarn along weft and warp direction.

b. Fabric stage: this type of bled is takes place at weaving stage i.e. the weft and warp yarns are made from different fibers or the weft and warp yarns have different constituents of fibers Table 4. 


\begin{tabular}{|c|c|c|c|c|c|c|c|c|c|}
\hline \multirow{2}{*}{15} & Warp & d & 1 & 1 & $\mathrm{~d}$ & 1 & 0.55 & 0.55 & 1 \\
\hline & Weft & $\mathrm{d}$ & 0.62 & 0.61 & $\mathrm{~d}$ & 0.60 & 0.70 & 0.71 & 1 \\
\hline \multirow{2}{*}{16} & Warp & 0.65 & 0.346 & 0.75 & 0.65 & 1 & 1 & 1 & 1 \\
\hline & Weft & 0.65 & 0.35 & 0.75 & 0.65 & 1 & 1 & 1 & 1 \\
\hline \multirow{2}{*}{17} & Warp & 0.72 & 0.78 & 1 & 0.22 & 1 & 1 & 1 & 1 \\
\hline & Weft & 0.72 & 0.79 & 1 & 0.22 & 1 & 1 & 1 & 1 \\
\hline \multirow{2}{*}{18} & Warp & 1 & $\mathrm{~d}$ & 1 & 1 & 1 & 1 & 1 & 1 \\
\hline & Weft & 1 & d & 1 & 1 & 1 & 1 & 1 & 1 \\
\hline \multirow{2}{*}{19} & Warp & 1 & d & 1 & 1 & 1 & 1 & 1 & 1 \\
\hline & Weft & 1 & d & 1 & 1 & 1 & 1 & 1 & 1 \\
\hline \multirow{2}{*}{20} & Warp & d & 1 & 1 & $d$ & 1 & 1 & 1 & 1 \\
\hline & Weft & 1 & $\mathrm{~d}$ & 1 & 1 & 1 & 1 & 1 & 1 \\
\hline
\end{tabular}

\section{Qualitative Components}

Table 5: Qualitative components of the fabrics.

\begin{tabular}{|c|c|c|c|}
\hline Sample No. & Components blended & Sample No. & Components blended \\
\hline 1 & Polyester & 11 & Polyester + Cotton + Nylon \\
\hline 2 & Polyester + Cotton & 12 & Polyester \\
\hline 3 & Acrylic & 13 & Polyester + Wool \\
\hline 4 & Polyester + Silk & 14 & Polyester + Cotton \\
\hline 5 & Polyester & 15 & Nylon + Cotton + Silk \\
\hline 6 & Acrylic + Nylon + Spandex & 16 & Polyester + Wool +Cotton \\
\hline 7 & Polyester & 17 & Polyester + Acrylic + Cotton \\
\hline 8 & Nylon + Polyester & 18 & Polyester \\
\hline 9 & Polyester + Acrylic & 19 & Polyester \\
\hline 10 & Acrylic + Nylon + Spandex & 20 & Polyester + Cotton \\
\hline
\end{tabular}

Qualitative component of the fabric is content of the fabric i.e., the fabric from what type of fiber is made which is represented by word without definite amount of contents of the fibers. The result we have obtained is below in the Table 5.

\section{Quantitative component (blend ratio analysis by Calculation)}

Quantitative component is defined as way of expressing the composition of fibers found in unknown fabric by numerical percentage. Then as we have done in this project the fabrics have different types of fibers and composition percents.

$C 1=\left(\frac{M 1}{M 2}\right) * 100 \%$ Where, $\mathrm{M} 1=$ Mass of the dried insoluble fibers, $\mathrm{M}=$ Mass of the dried initial specimen, $\mathrm{C} 1=$ Blend ratio of the dried insoluble fibers (\%), 100-C1=Blend ratio of the dissolved fiber (\%).

\section{Formula for calculation of quantitative components}

PPC $=$ picks per centimeter i.e. number of yarns in weft direction

$\mathrm{EPC}=$ ends per centimeter i.e. number of yarns in warp direction

$\mathrm{A}=$ Weight of one warp in $\mathrm{mg}, \mathrm{B}=$ Weight of one weft in $\mathrm{mg}$
$\mathrm{K} 1$ = percentage value of first warp fibers, $\mathrm{L} 1$ = percentage value of second warp fibers

$\mathrm{K} 2$ = percentage value of first weft fibers, L2 = percentage value of second weft fiber

$M=$ percentage value of third weft fibers

Since there are PPC numbers of weft yarns in one centimeter and EPC number warp yarns in one centimeter, then:

Weft $/ \mathrm{cm}$ in $\mathrm{mg}=P P C^{*} B=P B$ and

Warp $/ \mathrm{cm}$ in $\mathrm{mg}=E P C^{*} A=E A$

Weight of first warp fiber in $\mathrm{mg} / \mathrm{cm}=\frac{K 1}{100} * E A=X p$ Weight of second warp fiber in $\mathrm{mg} / \mathrm{cm}=\frac{L 1}{100} * E A=Y p$ Weight of first weft fiber in $\mathrm{mg} / \mathrm{cm}=\frac{K 2}{100} * P B=X t$ Weight of second weft fiber in $\mathrm{mg} / \mathrm{cm}=\frac{L 2}{100} * P B=Y t$ Weight of third weft fiber in $\mathrm{mg} / \mathrm{cm}=\frac{M}{100} * P B=Z t$

Quantitative component or blend ratio of the first fiber $=$ $\frac{X p+X t}{P B+E A} * 100 \%=Q \%$ Quantitative component or blend ratio of the second fiber $=\frac{Y p+Y t}{P B+P A} * 100=R \%$ Quantitative component or blend ratio of the third fiber $=\frac{Z t}{P B+E A} * 100=S \%$ 


\section{Current Trends in Fashion Technology \& Textile Engineering}

Therefore the fabric is a blend of $\mathrm{Q} \%, \mathrm{R} \%$ and $\mathrm{S} \%$ of first, second and third fiber respectively.

Example 1: for sample 17

Warp: $\frac{1-(0.22+0.28)}{1} * 100 \% \Rightarrow 50 \% \quad$ Acrylic, $\quad \frac{0.22}{1} * 100 \% \Rightarrow 22 \%$

polyester and $\frac{0.28}{1} * 100 \% \Rightarrow 28 \%$ Cotton

Weft: $\quad \frac{1-(0.21+0.28)}{1} * 100 \% \Rightarrow 51 \% \quad$ Acrylic, $\frac{0.21}{1} * 100 \% \Rightarrow 21 \%$ polyester and $\frac{0.28}{1} * 100 \% \Rightarrow 28 \%$ Cotton, therefore the fabric is a blend of: $\frac{50 \%+51 \%}{2}=50.5 \%$ acrylic, polyester and $28 \%$ cotton.

Example 2: for sample 15

$P P C=24, E P C=30,10$ warp $=3.68 \mathrm{mg} 10$ weft $=4.06 \mathrm{mg}$

Warp: $45 \%$ nylon, $55 \%$ cotton

Weft: $\quad \frac{30+29}{2}=29.5 \%$ Nylon, $\quad 61-29.5=30.5 \quad \%$ Cotton,

$100-(30.5+29.5)=40 \%$ Silk

Table 6: Quantitative comments of fabrics obtained.

\begin{tabular}{|c|c|c|c|c|}
\hline \multirow{2}{*}{ Sample No. } & \multirow{2}{*}{ Qualitative Components } & \multicolumn{3}{|c|}{ Quantitative Components } \\
\hline & & Warp & Weft & Fabric \\
\hline 1 & Polyester & $100 \%$ & $100 \%$ & $100 \%$ \\
\hline 2 & Polyester/Cotton & $21.33 / 78.67$ & $20.5 / 79.67$ & $21 / 79$ \\
\hline 3 & Acrylic & $100 \%$ & $100 \%$ & $100 \%$ \\
\hline 4 & Polyester/Silk & $100 \%$ polyester & $91 / 8.75$ & $95.5 / 4.37$ \\
\hline 5 & Polyester & $100 \%$ & $100 \%$ & $100 \%$ \\
\hline 6 & Acrylic/Nylon/Spandex & $69 / 24 / 7$ & $69 / 24 / 7$ & $69 / 24 / 7$ \\
\hline 7 & Polyester & $100 \%$ & $100 \%$ & $100 \%$ \\
\hline 8 & Nylon/Polyester & $52 / 48$ & $51.5 / 49$ & $48.5 / 51.5$ \\
\hline 9 & Polyester/Acrylic & $55 / 44$ & $54 / 45$ & $54.5 / 44.5$ \\
\hline 10 & Acrylic/Nylon/Spandex & $71 / 22 / 7$ & $71 / 22 / 7$ & $71 / 22 / 7$ \\
\hline 11 & Polyester/Cotton/Nylon & $100 \%$ polyester & $41 / 39.5 / 19.5$ & $70.5 / 19.7 / 9.75$ \\
\hline 12 & Polyester & $100 \%$ & $100 \%$ & $100 \%$ \\
\hline 13 & Polyester/Wool & $50.5 / 49.5$ & $50.5 / 49.5$ & $50.5 / 49.5$ \\
\hline 14 & Polyester/Cotton & $54.67 / 45.3$ & $54.67 / 45.3$ & $54.6 / 45.3$ \\
\hline 15 & Nylon/Cotton/Silk & 49.8/60.72(nylon/cotton) & $22.03 / 29.57 / 38.78$ & $37.75 / 43.55 / 18.7$ \\
\hline 16 & Polyester/Wool/Cotton & $41 / 25 / 34.6$ & $41 / 25 / 35$ & $41 / 25 / 35$ \\
\hline 17 & Polyester/Acrylic/Cotton & $22 / 50 / 28$ & $21 / 51 / 28$ & $21.5 / 50.5 / 28$ \\
\hline 18 & Polyester & $100 \%$ & $100 \%$ & $100 \%$ \\
\hline 19 & Polyester & $100 \%$ & $100 \%$ & $100 \%$ \\
\hline 20 & Polyester/Cotton & $100 \%$ cotton & $100 \%$ polyester & $44.8 / 55.2$ \\
\hline
\end{tabular}

The discussion goes to identify any fabric or to analyze its percentage it should be in the sequence of feeling, burning, microscopic and finally solubility. By feeling characteristic estimation of the fabric whether it is made up of natural or synthetic fiber is possible and then by burning it is possible to distinguish in to definite groups i.e. possibility to identify Protein from cellulosic fibers and these from synthetic fibers. Following by microscope viewing some specific fibers are identified, like cotton and wool from any fiber. Finally solubility test will give definite specific fibers and blend ratio for blended fabrics, by this method any fiber is identified.
Since there are 24 weft yarns and 30 warp yarns in one centimeter, then the fabric has

$24 * \frac{4.06}{10}=9.696 \mathrm{mg} \mathrm{weft} / \mathrm{cm}, 30 * \frac{3.68}{10}=11.04 \mathrm{mg}$ warp $/ \mathrm{cm}$ cotton $/ \mathrm{cm}$

Weft: $\frac{29.5}{100} * 9.696=2.86032 \mathrm{mg}$ nylon $/ \mathrm{cm}, \frac{30.5}{100} * 9.696=2.95728$ $\mathrm{mg}$ cotton $/ \mathrm{cm}$ and $\frac{40}{100} * 9.696=3.8784 \mathrm{mg} \mathrm{silk} / \mathrm{cm}$

Then, the fabric is a blend of; $\frac{2.86032+4.968}{9.696+11.04} * 100 \%=37.75 \%$ Nylon, $\frac{2.95728+6.072}{9.696+11.04} * 100=43.55 \%$ Cotton and $\frac{3.8784}{9.696+11.04} * 100=18.70 \%$ Silk

With similar manner to these examples calculating the quantitative components of each fabric the following results obtained Table 6.
Warp: $\frac{45}{100} * 11.04=4.968 \mathrm{mg}$ nylon $/ \mathrm{cm}, \frac{55}{100} * 11.04=6.072 \mathrm{mg}$ 
obstacle for comfort. Sample 5 and 14 are stiff though they are serviceable and cost effective this leads to discomfort. Thus in our country light weight, soft fabrics are preferable due to the higher temperature condition. The fabrics dyes were striped with Acids, alkalis and reducing agents like acetic acid 5\% at boiling, hydrosulphite (5\%) with sodium hydroxide (1\%)at boiling, pyridine, $1 \%$ ammonia at boiling, ammonia and hydrosulphite and combination of these, but it could not stripped. this is may be due to the final finishing given to the fabrics. Identification of textile materials [3-5] says dyes can be striped using reducing agents like hydrosulphite (5\%) with sodium hydroxide $(1 \%)$, pyridine, acetic acid, ammonia, ammonia and hydrosulphite giving for specific types of dyes [6]. Pyridine used to remove disperse and direct dyes, 5\% boiling Acetic acid use to stripe basic dyes from wool and silk,1\% boiling Ammonia to remove acid dyes from silk and wool, sodium hypochlorite for any dye, and boiling sodium hydro-sulfite (5\%)+ Sodium hydroxide (1\%) for any dye.

\section{Conclusion}

Fibers can be identifying at fiber stag, yarn stage, before dying, before garment formation during marketing. To perform these identifications, the physical (strength, longitudinal and cross-sectional appearance, handle, absorbency, elasticity, drapability etc.,) and chemical properties (resistant to alkalis, acids and other specific chemicals, dye affinity, burning nature etc.) of the fibers being studying is important.

Now days so many similar chemical composition, textured, dyed and finishing agent are given fibers are producing [7]. These fibers are converted to fabrics in single component or combing two or more fibers. This combining system is called blending and the produced fabric is called bled fabric. Fibers are blended to obtain combed property, to reduce cost of expensive fibers and to fid decorative color effect of garments in coloration during fiber, yarn formation and fabric formation. Single or blended fabrics can be identified and analyzed by feeling, burning, microscope test, solubility staining, density etc.
Non-technical technical (feeling and burning) and technical (microscopic longitudinal appearance and solubility) tests are used to identify twenty different fabrics of ladies skirt, which are mostly wear by Ethiopian ladies and then we have calculated the qualitative and quantitative components of all the fibers [8].

From the result most of Ethiopian ladies skirt fabrics are made of synthetic fibers like polyester, acrylic and nylon and a blend of these fibers with wool and cotton. This shows these kinds of fabrics are imported to satisfy the demand of the customers.

The Ethiopian textile industries have to produce polyester, nylon and acrylic fibers and blend of these with natural fibers like cotton and wool in enough quantity for the future, since fabrics made of these fibers are cost effective, good serviceable and highly demanded by the Ethiopian ladies. If these fabrics will produced there will be additional advantage to our country since market will be in local exchange for both the customer and country's economy.

\section{References}

1. Koblyakov A (1989) Laboratory practice in the study of textile materials. Union of Soviet Socialist Republics 67-71.

2. Bernard PC (1983) Textiles: Fiber to Fabric. ( $6^{\text {th }}$ edn), Mc GRAW-HILL Inc., 252-466 \& 552-569.

3. Carolyn AF (1975) Identification of Textile Materials. $\left(7^{\text {th }}\right.$ edn), The Textile Inc., 1-22, 51-117 \& 182.

4. Jothi D (2000) A textbook of fiber science and technology. Bahir Dar University, 4-10, 79-239 and 347-357.

5. Jothi D (1999) Hand Book of textiles for finishers. Bahir Dar University I, 2 and 17.

6. Erika Schaffer (1981) Fiber Identification in Ethnological Textile Artifacts. International Institute for Conservation of Historic and Artistic Works 26(3): 119-129.

7. Sang-Song L (2002) Five Simple Tests for Fiber ID. Textile Research J $1-2$.

8. Phyllis GT, Billie JC (1997) Understanding textiles. ( $5^{\text {th }}$ edn), Prentice Hall Inc., 27 \& 73-117.

\section{Your next submission with Juniper Publishers} will reach you the below assets

- Quality Editorial service

- Swift Peer Review

- Reprints availability

- E-prints Service

- Manuscript Podcast for convenient understanding

- Global attainment for your research

- Manuscript accessibility in different formats

( Pdf, E-pub, Full Text, Audio)

- Unceasing customer service

Track the below URL for one-step submission https://juniperpublishers.com/online-submission.php 